Acta Horticulturae et Regiotecturae 2

Nitra, Slovaca Universitas Agriculturae Nitriae, 2018, pp. 42-47

\title{
EFFECTS OF GIBBERELLIC ACID AND LOW TEMPERATURE ON GERMINATION OF SOME PRUNUS SPECIES EMBRYOS (WITHOUT COTYLEDONS) UNDER LABORATORY CONDITIONS
}

\author{
Mahmoud. A. GHAYYAD* \\ Damascus University, Syria
}

\begin{abstract}
Seeds of Prunus species do not germinate as a result of different mechanisms of dormancy such as physiological, physical and/ or chemical ones. This study was carried out in order to determine the effects of three concentrations of Gibberellic acid (GA $\left.)_{3}\right) 1$, 3 , and $5 \mathrm{mg} \cdot \mathrm{L}^{-1}$ and low temperature at $5^{\circ} \mathrm{C}$ on germination and on the length of isolated embryos from cotyledons of almond, apricot, plum, peach, mahaleb and sweet cherry on top of filter paper under laboratory conditions. The highest germination percentage (96.67\%) was at $1 \mathrm{mg} \cdot \mathrm{L}^{-1} \mathrm{GA}_{3}$ without cold treatment or $3 \mathrm{mg} \cdot \mathrm{L}^{-1} \mathrm{GA}_{3}+$ cold treatment in almond, the highest length of embryos $\left(15.47 \mathrm{~mm}\right.$ ) was also in almond at $1 \mathrm{mg}^{-L^{-1}} \mathrm{GA}_{3}$ without cold treatment. Embryos of mahaleb and sweet cherry germinated at low germination percentages of $31.16 \%, 33.33 \%$ respectively at $3 \mathrm{mg} \cdot \mathrm{L}^{-1} \mathrm{GA}_{3}+$ cold treatment. It was concluded that embryos of almond, apricot, plum and peach were germinated successfully on top of filter paper under laboratory conditions and $\mathrm{GA}_{3}$ increased significantly the germination percentages of the isolated embryos either after cold treatment or without compared with controls. A strong positive correlation was found between seed germination without testa, embryos germination and final embryos length simultaneously.
\end{abstract}

Keywords: Prunus, isolated embryos, $\mathrm{GA}_{3}$, cold treatment, filter paper, laboratory conditions

Seeds of Prunus species do not germinate immediately when planted, either in the field or in the laboratory, as a result of different mechanisms of dormancy such as physiological (embryo), physical (endocarp), chemical (inhibitors) ones or the combinations of mentioned mechanisms; dormancy in these species may last for several months.

The germination inhibitors exist at different concentrations in various parts of seed, including pericarp, seedcoat, cotyledons, and embryo. The proportion of inhibitors could be decreased by removing either one or several parts of the seeds and thus germination percentage could be increased (San and Yildirim, 2009). On the other hand, cold stratification of seeds for several months could overcome dormancy. Also, some growth regulators such as $\mathrm{GA}_{3}$ were used to induce the germination of the seeds of some species, for example P. mahaleb (Ghayyad et al., 2010; Gercekcioğlu and Cekic, 1999; Pipinis et al., 2012).

Overcoming seed dormancy in vitro germination was also successfully used in strawberry (Miller et al., 1992), citrus fruits (Hassanein and Azooz, 2003), walnut (Kaur et al., 2006), and almond (San and Yildirim, 2009). Germination of immature embryos has been successfully accomplished in some stone fruits including cherry (Hormaza, 1999), apricot (Ning et al., 2007), peach, almond, and peach×almond hybrids (Ledbetter et al., 1998).

A few studies have been carried out about in vitro germination of embryos isolated from cotyledons (Arbeloa et al., 2009; San and Yildirim, 2009), but all of the studies are based on MS medium and combinations of benzylaminopurine (BAP) and gibberellic acid $\left(\mathrm{GA}_{3}\right)$ and /or Indol butyric acid (IBA). San et al. (2014) reported that for successful in vitro embryo germination, the MS medium should be fortified with $0.5 \mathrm{mg} \cdot \mathrm{L}^{-1} \mathrm{BAP}+3.0 \mathrm{mg} \cdot \mathrm{L}^{-1} \mathrm{GA}_{3}$ in apricot, peach, and wild cherry. Payghamzadeh and Kazemitabar (2010a) reported that the best performing medium for immature embryos germination walnut was DKW basal medium supplemented with $1 \mathrm{mg} \mathrm{L}^{-1}$ alone and $1.5 \mathrm{mg} \mathrm{L}^{-1}$ BAP in conjunction with $0.01,0.05$ and $0.1 \mathrm{mg} \mathrm{L}^{-1}$ IBA (germination ratios vary between $49.32 \%$ and $67.76 \%$ ). Kaur et al. (2006) reported that the best performing medium was MS with $0.5 \mathrm{mg} \cdot \mathrm{L}^{-1}$ kinetin, $0.5 \mathrm{mg} \cdot \mathrm{L}^{-1} \mathrm{BAP}$ and $2 \mathrm{mg} . \mathrm{L}^{-1}$ $\mathrm{GA}_{3}$ yielding $66.6 \%$ germination in Netar Akhrot cultivar of walnut after 12 days of culturing and the percent germination of immature embryos was higher when BAP and IBA were simultaneously applied as compared to those when applied separately (Kaur et al., 2006).

In addition, Kaur et al. (2006) used cold treatment in in vitro germination of immature walnut embryos, and the per cent germination of excised embryos was higher when $\mathrm{GA}_{3}$ and cold treatments were simultaneously applied as compared to those when applied separately.

The object of this study is to determine the effects of Gibberellic acid $\left(\mathrm{GA}_{3}\right)$ and low temperature on germination of isolated embryos from cotyledons of almond, apricot, plum, peach, mahaleb and sweet cherry on top of paper under laboratory conditions without the need for nutritious medium and the easy and rapid assessment of embryos growth under simple conditions. 


\section{Material and methods}

This study was carried out in 2017 during Summer and Autumn in Damascus Countryside - Beit Tima Seed Scientific Research Laboratory.

Seeds of six Prunus species were collected: almond (Prunus amygdalus L.), apricot (Prunus armeniaca L.), plum (Prunus domestica L.), peach (Prunus persica L.), Mahaleb (Prunus mahaleb L.), and sweet cherry (Prunus avium L.). Fruits were collected in the same year of the study, then the seeds were isolated from mature fruits and dried at laboratory temperature $\left(20-25^{\circ} \mathrm{C}\right)$ for a month before they were used in the tests.

At first, hard endocarps were removed using a small hammer, then seeds were soaked in sterilized water for 48 hours for easy removal of testa and embryos, water being replaced every 12 hours.

After the testa (seedcoat) was removed, seeds with and without testa were incubated on top of filter paper under laboratory conditions in petri dishes without any pre-treatments as controls to compare with other treatments.

The embryos were carefully excised from the cotyledons under sterile conditions and were cultured on top of filter paper under laboratory conditions (temperature $20-25^{\circ} \mathrm{C}$, 16 hours a day and 8 hours a night) in petri dishes and submitted to the following treatments for three (3) weeks. Each treatment consisted of three (3) replications and each one contained tow (2) petri dishes with 10 embryos in each petri dish.

\section{Gibberellic acid $\left(\mathrm{GA}_{3}\right)$}

Embryos were moistened with three (3) different concentrations $\left(1,3\right.$, and $\left.5 \mathrm{mg} \cdot \mathrm{L}^{-1}\right)$ of $\mathrm{GA}_{3}$ solutions during the three weeks test (when needed).

\section{Cold treatment (low temperature)}

Embryos were kept in the refrigerator for three (3) weeks at $5{ }^{\circ} \mathrm{C}$ and moistened with distilled water when needed, after that embryos were tested under laboratory conditions.

\section{$\mathrm{GA}_{3}+$ cold treatment}

Embryos were moistened with the three (3) concentrations $\left(1,3\right.$, and $\left.5 \mathrm{mg} \cdot \mathrm{L}^{-1}\right)$ of $\mathrm{GA}_{3}$ solutions, then kept in the refrigerator for 3 weeks at $5{ }^{\circ} \mathrm{C}$ and moistened with $\mathrm{GA}_{3}$ when needed, then tested in laboratory conditions.

At the end of the tests, the results of the germinated embryos were recorded in table (1) as percentages. Also, the final length of the germinated embryos (root and shoots) was measured in order to examine how different species of embryo growth are affected by the different treatments. The results were recorded in table (2).

\section{Statistical analysis}

Embryo germination percentages were transformed using ArcSin (Square root $(X)$ ). Since transformed data must meet the assumption of normality, data normality was determined by Kolmogorov-Smirnov test of variances, factorial ANOVA was performed to test the main effects and interactions between the studied factors (species 6 levels $\times \mathrm{GA}_{3}$ concentrations 4 levels $\times$ cold treatment/without cold treatment 2 levels $\times 3$ replications). For comparing the germination of the isolated embryos with seed germination,

Table 1

Effects of $\mathrm{GA}_{3}$ and cold treartments on embryos with and without cotyledons germination on top of filter paper under laboratory conditions

\begin{tabular}{|c|c|c|c|c|c|c|c|c|}
\hline \multicolumn{9}{|c|}{ Seed germination percentage with cotyledons (\%) } \\
\hline \multirow{2}{*}{\multicolumn{2}{|c|}{ Treatments }} & \multicolumn{6}{|c|}{ species } & \multirow{2}{*}{ average } \\
\hline & & almond & apricot & plum & peach & mahaleb & cherry & \\
\hline \multicolumn{2}{|c|}{ Seed with testa } & 0 & 0 & 0 & 0 & 0 & 0 & 0 \\
\hline \multicolumn{2}{|c|}{ Seed without testa } & 81.67 & 60 & 70 & 66.67 & 35 & 28.33 & 56.94 \\
\hline \multicolumn{9}{|c|}{ Embryo germination percentage without cotyledons (\%) } \\
\hline \multicolumn{2}{|l|}{ Treatments } & \multicolumn{6}{|c|}{ species } & \multirow{2}{*}{ average } \\
\hline $\mathrm{GA}_{3}\left(\mathrm{mg} \cdot \mathrm{L}^{-1}\right)$ & cold treatment $5^{\circ} \mathrm{C}$ & almond & apricot & plum & peach & mahaleb & cherry & \\
\hline 0 & 0 week & $76.66 \mathrm{bL}$ & $48.33 \mathrm{bM}$ & $13.33 \mathrm{cN}$ & $16.67 \mathrm{bN}$ & $15.00 \mathrm{bN}$ & $10.00 \mathrm{bN}$ & 30.00 \\
\hline 1 & 0 week & $96.67 \mathrm{aL}$ & $91.67 \mathrm{aL}$ & $71.16 \mathrm{aM}$ & $68.83 \mathrm{aM}$ & $25.00 \mathrm{aN}$ & $30.00 \mathrm{aN}$ & 63.88 \\
\hline 3 & 0 week & $95.00 \mathrm{aL}$ & $90.00 \mathrm{aL}$ & 61.67aM & $65.00 \mathrm{aM}$ & $20.00 \mathrm{aN}$ & $31.67 \mathrm{aN}$ & 60.55 \\
\hline 5 & 0 week & $91.67 \mathrm{aL}$ & 81.16aLM & 73.33aLM & 66.67aLM & $21.67 \mathrm{aN}$ & $20.00 \mathrm{aN}$ & 59.08 \\
\hline 0 & 3 week & $40.00 \mathrm{cL}$ & $40.00 \mathrm{dL}$ & $36.67 \mathrm{bL}$ & $35.00 \mathrm{bL}$ & $13.33 \mathrm{bM}$ & $11.67 \mathrm{bM}$ & 29.44 \\
\hline 1 & 3 week & 83.33aL & 80.00aL & 80.00aL & 76.67aL & 31.16aM & 33.33aM & 64.08 \\
\hline 3 & 3 week & $96.67 \mathrm{aL}$ & $51.67 \mathrm{bcdN}$ & 80.00aL & 70.00aM & $15.00 \mathrm{bO}$ & $11.67 \mathrm{bO}$ & 54.17 \\
\hline 5 & 3 week & $90.00 \mathrm{aL}$ & $60.00 \mathrm{cbM}$ & 73.33aLM & 71.67aLM & $13.33 \mathrm{bN}$ & $10.00 \mathrm{bN}$ & 53.05 \\
\hline \multicolumn{2}{|l|}{ Average } & 83.52 & 66.98 & 62.16 & 59.68 & 21.05 & 20.74 & \\
\hline
\end{tabular}

Means with the same letters of $a, b, c, d$ in the same column are not significantly different at $\alpha=0.05$. Means with the same letters of $\mathrm{L}, \mathrm{M}, \mathrm{N}, \mathrm{O}$ in the same row are not significantly different at $\alpha=0.05$ 
factorial ANOVA (species 6 levels $\times$ treatments 9 levels $\times 3$ replications) was also performed. The Tukey HSD test at ( $\alpha=0.05$ ) was used as a multiple comparison procedure after ANOVA analysis. Data analysis was performed by using Microsoft Excel 2007 and Statistical.8 StatSoft, Inc Program. The results were presented after back-transform data by using $(\operatorname{Sin}(x)) 2$.

\section{Results and discussion}

Table 1 shows the germination percentages of seeds with cotyledons (without testa) and isolated embryos germinated on different concentrations of $\mathrm{GA}_{3}$ and cold treatment under the laboratory conditions on top of filter paper in almond, apricot, plum, peach, mahaleb and sweet cherry.

Seeds with testa did not germinate on filter paper under laboratory conditions in all studied species. The highest germination percentage of the seeds without testa was recorded for almond, then for plum, peach, apricot, mahaleb and sweet cherry simultaneously, but according to the Tukey test at ( $\alpha=0.05)$ there were no significant differences between almond and plum, apricot and peach, and mahaleb and cherry.

Factorial ANOVA results showed that the final germination of the isolated embryos was significantly affected by the species $(F(5,96)=542.72, p<0.001)$, by the $\mathrm{GA}_{3}$ concentrations $(F(3,96)=266.56, p<0.001)$, by the interaction of species and $\mathrm{GA}_{3}(F(15,96)=16.166, p<0.001)$, by the type of cold treatment $(F(1,96)=11.888, p<0.001)$, by the interaction of species and the type of cold treatment $(F(5,96)=30.238, p<0.001)$ and by the interaction of all of these factors $(F(15,96)=6.9483, p<0.001)$.

Results of the Tukey test $(\alpha=0.05)$ showed that germination percentage of almond was significantly the highest followed by apricot, plum and peach, and mahaleb and cherry. Germination percentage at $1 \mathrm{mg} . \mathrm{L}^{-1}$ of $\mathrm{GA}_{3}$ was significantly the best. For the concentrations 3 and $5 \mathrm{mg} \cdot \mathrm{L}^{-1}$ there were no significant differences, control was the lowest. Germination percentages of the incubated embryos without cold treatment were significantly higher than after cold treatment.

There were no significant effects of 1,3 or $5 \mathrm{mg} \cdot \mathrm{L}^{-1}$ concentrations of $\mathrm{GA}_{3}$ for almond, plum and peach, meanwhile the concentration of $1 \mathrm{mg}^{-1}$ was significantly higher than the others on apricot, mahaleb and cherry.

Germination percentages of almond and apricot embryos without cold treatment were significantly higher than those after cold treatment and in reverse for plum and peach, whereas there were no significant effects on mahaleb and cherry.

The highest germination percentage $(96.67 \%)$ was at $1 \mathrm{mg} \cdot \mathrm{L}^{-1} \mathrm{GA}_{3}$ without cold treatment and $3 \mathrm{mg} \cdot \mathrm{L}^{-1} \mathrm{GA}_{3}+$ cold treatment in almond. However, the differences between the germination percentages obtained from cold treatment and $\mathrm{GA}_{3}$ were not statistically significant. The highest germination percentage $(91.67 \%)$ was $1 \mathrm{mg} \cdot \mathrm{L}^{-1} \mathrm{GA}_{3}+$ cold treatment in apricot, in plum 1 or $3 \mathrm{mg} \cdot \mathrm{L}^{-1} \mathrm{GA}_{3}+$ cold

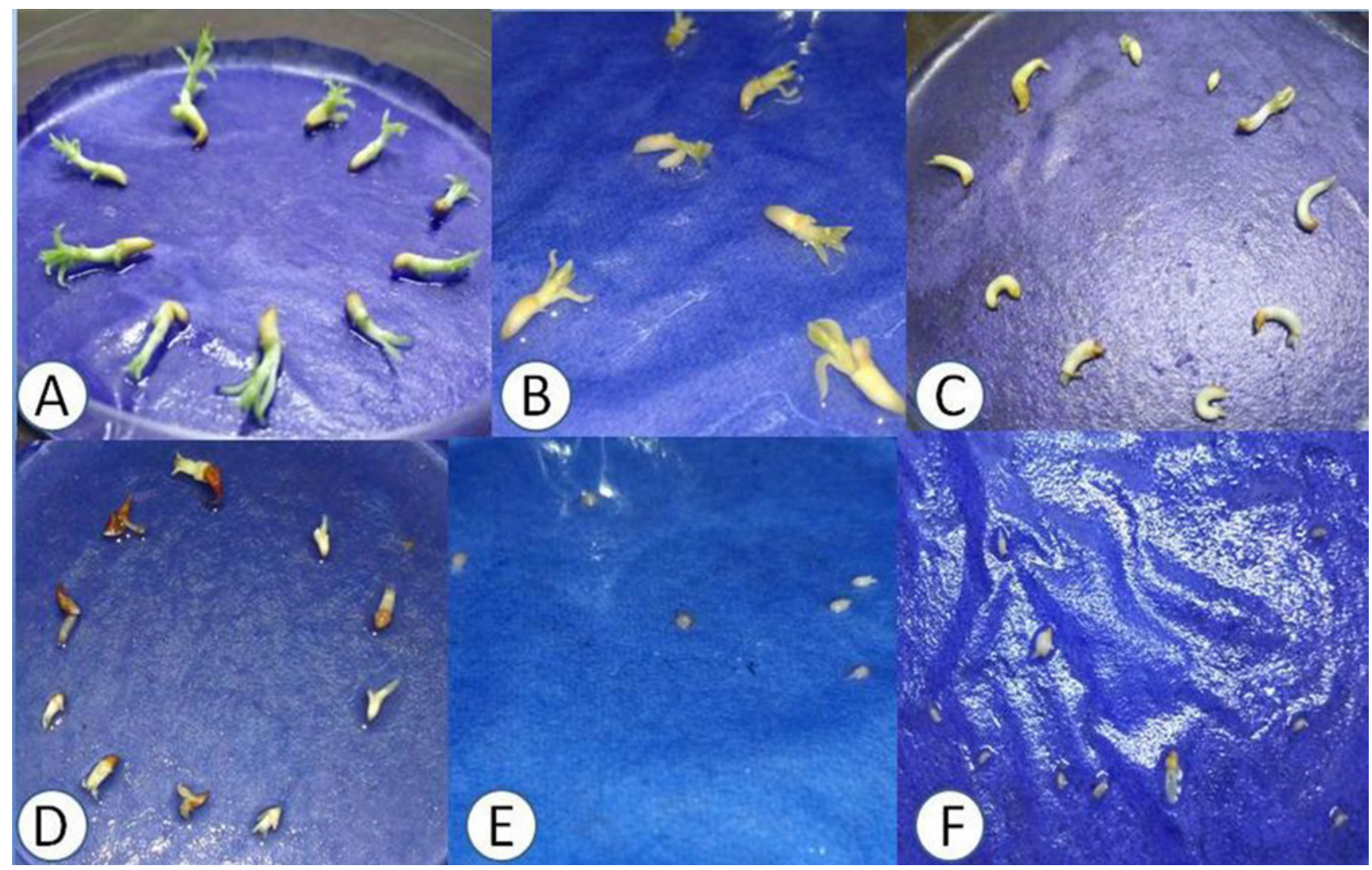

Figure 1 Embryos germination of some Prunus species without cotyledons on top of filter paper (FP) under laboratory conditions (A) almond embryos on $\mathrm{FP}+\mathrm{GA}_{3} 1 \mathrm{mg} \cdot \mathrm{L}^{-1}$ without cold treatment. (B) apricot embryos on $\mathrm{FP}+\mathrm{GA}_{3} 1 \mathrm{mg}^{-\mathrm{L}^{-1}}$ without cold treatment, (C) plum embryos on FP $+\mathrm{GA}_{3} 3 \mathrm{mg} \cdot \mathrm{L}^{-1}+$ cold treatment, (D) peach embryos on $\mathrm{FP}+\mathrm{GA}_{3} 1 \mathrm{mg} \cdot \mathrm{L}^{-1}+$ cold treatment, (E) mahaleb embryos on $\mathrm{FP}+\mathrm{GA}_{3} 1 \mathrm{mg} \cdot \mathrm{L}^{-1}+$ cold treatment, $(\mathrm{F})$ sweet cherry embryos on $\mathrm{FP}+\mathrm{GA}_{3} 1 \mathrm{mg}^{-\mathrm{L}^{-1}}+$ cold treatment 
treatment (80\%), meanwhile $1 \mathrm{mg} \cdot \mathrm{L}^{-1} \mathrm{GA}_{3}+$ cold treatment in peach, mahaleb and cherry $(76.67 \%, 31.16 \%$, and $33.33 \%$ respectively), it was noted that only the root germinated in plum.

The results obtained in this study showed that seeds with testa did not germinate. Removing the testa increased the final germination percentage, this agrees with the fact that in some species, dormancy is overcomed by removing from seed coats that are likely to contain substances that inhibit embryo growth including Malus, Prunus, and Pyrus (Johnson and Chirco, 2003), while San et al. (2014) reported that seeds with cotyledons and/or testa of apricot, peach, and wild cherry did not germinate on the MS medium without cold treatment or stratification.

Isolated embryos of almond, apricot, plum and peach germinated on top of filter paper successfully in spite of the facts that tests were carried out under laboratory conditions (Figure 1 shows the isolated embryos from cotyledons germination of the studied species). Isolated embryos of mahaleb and sweet cherry did not germinate very satisfactorily. Likewise, seeds without testa also germinated at low germination ratios, that may be related to combined dormancy (Embryo not fully developed when seed shed with physiological germination block, Geneve, 1999). Roots of plum germinated, but shoots did not either after cold treatment or without, this may indicate to the Epicotyl dormancy in plum since the same was noted in seeds without testa test.

In all species, gibberellic acid $\left(\mathrm{GA}_{3}\right)$ significantly increased the germination percentages of the isolated embryos either after cold treatment or without comparing with controls; these results agree with Hartmann et al. (1997) in the rule of gibberellin in overcoming physiological dormancy in seeds with dormant embryos, but there was no significant effect of the addition of gibberellic acid on embryos germination; Payghamzadeh and Kazemitabar (2010a) reported that in the free PGR (plant growth regulators) medium embryos of walnut germinated, but did not induce any embryo development.

The interaction of species and cold treatment from statistical standpoint showed that germination of plum (only root) and peach isolated embryos was effected positively by the cold treatment, which means roots germinated after cold treatment, shoot remained dormant, and according to Geneve (1999) this may also indicate the Epicotyl and radicle dormancy. Meanwhile, embryos of almond and apricot were germinated better without cold treatment, there was no effect of cold treatment on mahaleb and sweet cherry embryos, the changes in the last two species were only turgidity of the root, that may relate to embryo dormancy which did not overcome completely. In all species and in general, there was no significant effect of $\mathrm{GA}_{3}+$ cold treatment on germination embryos compared with only $\mathrm{GA}_{3}$; this means that the main effect on germination was for $\mathrm{GA}_{3}$, and for plum, peach, mahaleb and sweet cherry there was maximum embryo germination percentages of $80 \%$, $76 \%, 67 \%, 31.16 \%$ and $33.33 \%$ respectively.

\section{Embryo length (shoots and roots)}

Table 2 shows the mean length of the germinated embryos for almond, apricot, plum, peach, mahaleb and sweet cherry on filter paper under laboratory conditions at the end of the tests.

Factorial ANOVA results showed that there were significant differences betweeen the length of the germinated embryos of the studied species $(F(5,96)=$ $1,711.4, p<0.001), \mathrm{GA}_{3}$ concentrations $(F(3,96)=137.01$, $p<0.001)$ The type of cold treatment $F(15,96)=17.873$, $p<0.001)$, the interaction of species and the type of cold treatment $(F(5,96)=90.297, p<0.001)$, and the interaction of all of these factors $(F(15,96)=22.348, p<0.001)$.

Results of the Tukey test $(\alpha=0.05)$ showed that the highest length of germinated embryos was significant in almonds, followed by apricot and peach, plum, cherry and then mahaleb.

The highest length of the germinated embryos was shown at 1 or $3 \mathrm{mg} \cdot \mathrm{L}^{-1}$ of $\mathrm{GA}_{3}$ concentration, whereas the control reached the lowest length. The length of the incubated embryos without cold treatment was significantly higher compared to the cold treatment, and the length of almond, apricot, peach and cherry embryos without cold treatment was significantly higher than after cold treatment,

Table 2 The mean final length of the germinated embryos (root and shoots $\mathrm{mm}$ ) after 3 weeks incubation

\begin{tabular}{|c|c|c|c|c|c|c|c|c|}
\hline \multicolumn{2}{|c|}{ Treatments } & \multicolumn{6}{|c|}{ Species } & \multirow{2}{*}{ average } \\
\hline $\mathrm{GA}_{3}\left(\mathrm{mg} \cdot \mathrm{L}^{-1}\right)$ & cold treatment $5^{\circ} \mathrm{C}$ & almond & apricot & plum & peach & mahaleb & cherry & \\
\hline 0 & 0 week & $11.50 \mathrm{bL}$ & $7.14 \mathrm{bM}$ & $6.00 \mathrm{bM}$ & $6.17 \mathrm{bM}$ & $1.67 a b N$ & $2.67 \mathrm{bN}$ & 6.19 \\
\hline 1 & 0 week & 15.47aL & $8.50 \mathrm{aM}$ & $6.17 \mathrm{bN}$ & $8.33 \mathrm{aM}$ & $3.00 \mathrm{aO}$ & $3.56 \mathrm{aO}$ & 7.51 \\
\hline 3 & 0 week & 14.77aL & $9.10 \mathrm{aM}$ & $50.80 \mathrm{bN}$ & 5.58aM & 2.89aP & $3.89 \mathrm{aO}$ & 7.51 \\
\hline 5 & 0 week & $12.56 \mathrm{bL}$ & $6.92 \mathrm{bM}$ & 7.11abM & $7.61 \mathrm{aM}$ & $2.83 \mathrm{aN}$ & $3.5 \mathrm{aN}$ & 6.75 \\
\hline 0 & 3 week & $7.33 \mathrm{dL}$ & $7.25 \mathrm{bL}$ & $4.00 \mathrm{~cm}$ & $3.42 \mathrm{cM}$ & $2.00 \mathrm{nN}$ & $2.00 \mathrm{aN}$ & 4.33 \\
\hline 1 & 3 week & $9.75 \mathrm{bcL}$ & $5.87 \mathrm{bcN}$ & $8.13 \mathrm{aM}$ & $6.67 \mathrm{bN}$ & $2.56 \mathrm{aO}$ & $2.33 \mathrm{aO}$ & 5.88 \\
\hline 3 & 3 week & $10.70 \mathrm{bL}$ & $4.80 \mathrm{cO}$ & $8.25 \mathrm{aM}$ & $6.73 \mathrm{bN}$ & $2.33 \mathrm{aP}$ & $3.00 \mathrm{aP}$ & 5.97 \\
\hline 5 & 3 week & $11.11 \mathrm{bL}$ & $5.28 \mathrm{cM}$ & $6.19 \mathrm{bM}$ & $6.28 \mathrm{bM}$ & $2.67 \mathrm{aN}$ & $2.67 \mathrm{bN}$ & 5.70 \\
\hline \multicolumn{2}{|l|}{ Average } & 11.65 & 6.86 & 6.46 & 6.72 & 2.50 & 2.95 & \\
\hline
\end{tabular}




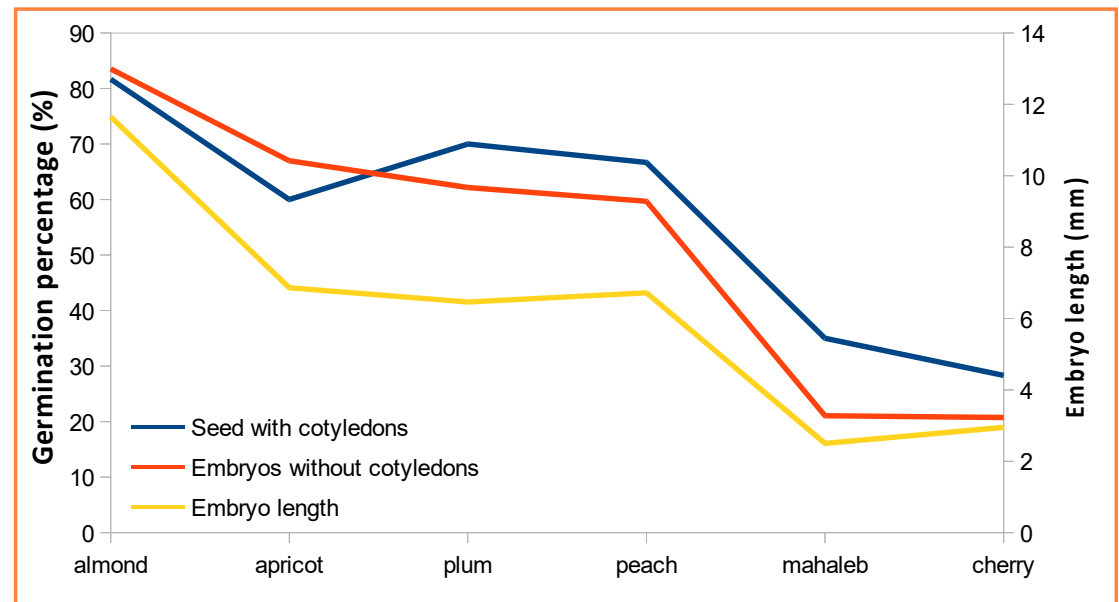

Figure 2 The mean seed germination percentages of the species with cotyledons, the mean isolated embryos germination percentages without cotyledons and the mean final embryos length

whereas there were nt significant differences in plum and mahaleb.

The highest length was recorded in almond at 1 or $3 \mathrm{mg} \cdot \mathrm{L}^{-1} \mathrm{GA}_{3}$ without cold treatment $(15.47 \mathrm{~mm}, 14.77 \mathrm{~mm})$, the same for apricot, peach, mahaleb and cherry the highest length was at $3 \mathrm{mg} \cdot \mathrm{L}^{-1}$ without cold treatment. However, there were no significant differences between 1,3 , and 5 mg. $\mathrm{L}^{-1}$ without cold treatment for the three previous species, for plum the highest length was at 3 or $1 \mathrm{mg} \cdot \mathrm{L}^{-1}+$ cold treatment ( $8.25 \mathrm{~mm}, 8.13 \mathrm{~mm}$ ).

Gibberellin acid $\left(\mathrm{GA}_{3}\right)$ without cold treatment had a positive effect on the development of the embryos, except for plum embryos (only root) which had the best length after cold treatment with presence of $\mathrm{GA}_{3}$. In general, low temperatures seem to be favourable to the germination and embryo growth of plum because of the epicotyl dormancy. Payghamzadeh and Kazemitabar (2010b) reported that high frequency of plantlet of pecan embryos was reported in modified DKW basal medium supplemented with $1 \mathrm{mg} \mathrm{L}^{-1} \mathrm{BAP}, 0.05 \mathrm{mg} \mathrm{L}^{-1} \mathrm{IBA}$ and $2 \mathrm{mg} \mathrm{L}^{-1} \mathrm{GA}_{3}$ and dark culture condition.

In other study, Payghamzadeh and Kazemitabar (2010a) found out that the longest main shoot length of immature embryos of walnut was achieved in DKW medium supplemented with 1 and $1.5 \mathrm{mg} . \mathrm{L}^{-1}$ BAP.

Scaltsoyiannes et al. (1997) reported the effects of cytokinin (BA) and auxin (IBA) on shoot development.

A strong positive correlation was found between seed germination without testa (with cotyledons $x$ ) and embryos germination percentages of the species $(y)$ $(R=0.97)$, the simple linear correlation equation was $(y=1.19 x-15.53)$. On the other hand, a positive correlation was found between embryos germination $(x)$ (means of the species) and the final length of the germinated embryos ( $y)(R=0.95, y=0.12 x-0.2)$. (Figure 2 shows the relationship between seed germination with cotyledons, without cotyledons and embryos length). Subsequently, a positive correlation was found between seed germination without testa (with cotyledons $x$ ) and the final length of the germinated embryos $(y)$ $(R=0.92, y=0.15 x-2.13)$.

In this study, the strong positive correlation was found between seed germination percentage without testa (with cotyledons) and isolated embryos germination percentage, and the final length of germinated embryos; the more germination without testa, the more germination embryos without cotyledons, and the more length of embryos. These relationships may lead to the conclusion that inhibitors do not necessarily present in the cotyledons since the seeds were not stored and the inhibitors did not move from testa to the cotyledons or embryos according to the theory of the inhibitors movement during storage; in this case, the closest probability is that inhibitors are present in the embryos. Moreover, it was concluded that culturing isolated embryos from cotyledons depend on the range of the mother seed dormancy and viability.

These relationships give a clear idea about the nature of the dormancy and the approximate prediction of the embryos growth.

\section{Conclusions}

In conclusion, isolated embryos from cotyledons of almond, apricot, peach and plum (only root) were germinated successfully on top of filter paper under laboratory conditions without the need for nutritious medium.

In all species, gibberellic acid $\left(\mathrm{GA}_{3}\right)$ significantly increased the germination percentages of the isolated embryos either after cold treatment or without comparing with controls.

A strong positive correlation was found between seed germination without testa (with cotyledons), embryos germination and the final embryos length at the same time.

\section{Acknowledgement}

We gratefully thank the staff of the Seed Scientific Research Laboratory in Damascus countryside for their cooperation. This study was accomplished in spite of the hard conditions in the country.

\section{References}

ARBELOA, A. - DAORDEN, M.E. - GARCIA, E. - ANDREU, P. - MARIN, J.A. 2009. In vito culture of Myroplan (Prunus cerasifera Ehrh) embryos. In HortScience, 2009, no. 44, pp. 1672-1674.

GERCEKCIOGLU, R. - CEKIC, C. 1999. The effects of some treatments on germination of mahaleb (Prunus mahaleb L.) seeds. In Turkish J Agric Forestry, 1999, no. 23, pp. 145-150.

GENEVE, R.L. 1999. Seed dormancy in commercial vegetable and flower species. In Proc. Intl. Plant Prop. Soc., 1999, no. 49, pp. 248-254.

GHAYYAD, M. - KURBYSA, M. - NAPOLSY, G. 2010. Effect of endocarp removal, gibberelline, stratification and sulfuric acid on germination of Mahaleb (Prunus mahaleb L.) seeds. In American-Eurasian Journal of Agricultural and Environmental Science, 2010, no. 9, pp. 163-168 https:// www.idosi.org/aejaes/jaes9(2)/10.pdf

HARTMANN, H.T. - KESTER, D.E. - DAVIES, F. JR. - GENEVE, R.L.1997. Plant Propagation Principles and Practices. $6^{\text {th }}$ ed., New Jersey : Prentice Hall, 1997. 
HASSANEIN, A.M. - AZOOZ, M.M. 2003. Propagation of Citrus reticulata via in vitro seed germination and shoot cuttings. In Biol. Plant., 2003, no. 47, pp. 173-177.

HORMAZA, J.I. 1999. Early selection in cherry combining RAPDs with embryo culture. In Sci. Hort., 1999, no. 79, pp. 121-126.

JOHNSON, G. - CHIRCO, E. 2003. Excised embryo tests of peach, apple and pear. Proceedings of the ISTA Forest Tree and Shrub Seed Committee Workshop Prague - Průhonice, Czech Republic, October 20-22. Forestry and Game Management Research Institute Jiloviště-Strnady, CR and Forestry Commission Research Agency, UK. http://www.vulhm.cz/sites/File/vydavatelska_cinnost/ sborniky_a_dalsi_publikace/sbornik_ista.pdf

KAUR, R. - SHARMA, N. - KUMAR, K. - SHARMA, D.R. SHARMA, S.D. 2006. In vitro germination of walnut (Juglans regia L.) embryos. In Scientia Horticulturae, 2006, no. 109, pp. 385-388. http://citeseerx.ist.psu.edu/viewdoc/ download?doi=10.1.1.845.1786\&rep=rep1\&type =pdf

LEDBETTER, C.A. - PALMQUIST, D.A. - PETERSON, S.J. 1998. Germination and net in vitro growth of peach, almond, and peachalmond hybrid embryos in response to mannitol inclusion in the nutrient medium. In Euphytica, 1998, no. 103, pp. 243-250.

MILLER, A.R. - SCHEEREUS, J.C. - ERB, P.S. - CHANDLER, C.K. 1992. Enhanced strawberry seed germination through in vitro culture of cut achenes. In J. Amer. Soc. Hort. Sci., 1992, no. 117, pp. 313-316.

NING, G.G. - BAI, S.P. - BAO, M.Z. - LIU, L. 2007. Factors affecting plantlet regeneration from in vitro cultured immature embryos and cotyledons of Prunus mume 'Xue mei'. In In Vitro Cell. Dev. Biol. Plant, 2007 , no. 43 , pp. $225-230$.
PAYGHAMZADEH, K. - KAZEMITABAR, S.K. 2010a. The effects of BAP, IBA and genotypes on in vitro germination of immature walnut embryos. In International Journal of Plant Production, vol. 4, 2010, no. 4, pp. 309-322. http://ijpp.gau.ac.ir/article_714_ fe51cf9369d57b06b13921ab106e59b0.pdf

PAYGHAMZADEH, K. - KAZEMITABAR, S.K. 2010b. In vitro germination of Pecan (Carya illinoinensis) embryo. In Biharean Biologist, 2010, no. 4, pp. 37-43. http://biozoojournals.ro/bihbiol/ cont/v4n1/bb.041106.Kazemitabar.pdf

PIPINIS, E.-MILIOS, E. - MAVROKORDOPOULOU, O.-GKANATSIOU, C. - ASLANIDOU, M. - SMIRIS, P. 2012. Effect of pretreatments on seed germination of Prunus mahaleb L. In Not. Bot. Horti Agrobo., vol. 40, 2012, no. 2, pp. 183-189. http://www.notulaebotanicae.ro/ index.php/nbha/article/viewFile/7887/7022

SAN, B. - YILDIRIM, A.N. 2009. Seed and in vitro embryo germination in aged almond. In Seed Sci. and Technol., 2009, no. 37, pp. 365-371. https://doi.org/10.15258/sst.2009.37.2.10

SAN, P. - YILDIRIM, A.N. - YILDIRIM , F. 2014. An In Vitro Germination Technique for Some Stone Fruit Species: the Embryo Isolated from Cotyledons Successfully Germinated without Cold Pre-treatment of Seeds. In Hortscience, vol. 49, 2014, no. 3, pp. 294-296. http:// hortsci.ashspublications.org/content/49/3/294.full

SCALTSOYIANNES, A. - TSOULPHA, P. - PANETSOS, K.P. MOULALIS, D. 1997. Effect of genotype on micropropagation of walnut trees (Juglans regia L.). In Sil. Gen., 1997, no. 46, pp. 326-332. 